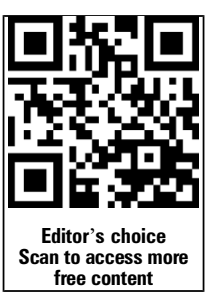

free content
${ }^{1}$ Department of Social and Behavioral Sciences, Center for Global Tobacco Control, Harvard School of Public Health, Boston, USA ${ }^{2}$ Department of Medicine, University of Ibadan, Ibadan, Nigeria

${ }^{3}$ School of Public Health, Imperial College London, London, UK

${ }^{4}$ Department of Social Medicine, Clinic of Social and Family Medicine, School of Medicine, University of Crete, Heraklion, Greece

\section{Correspondence to} Dr Israel T Agaku, Department of Social and Behavioral Sciences, Center for Global Tobacco Control, Harvard School of Public Health, Boston 02115, USA; iagaku@post.harvard.edu

Received 22 July 2014 Revised 29 September 2014 Accepted 30 September 2014 Published Online First 21 October 2014

\section{SLinked}

- http://dx.doi.org/10.1136/ tobaccocontrol-2014-052063

\section{CrossMark}

\footnotetext{
To cite: Agaku IT, Omaduvie UT, Filippidis FT, et al. Tob Control 2015;24: e233-e240.
}

\title{
Cigarette design and marketing features are associated with increased smoking susceptibility and perception of reduced harm among smokers in 27 EU countries
}

\author{
Israel T Agaku, ${ }^{1}$ Uyoyo T Omaduvie, ${ }^{2}$ Filippos T Filippidis, ${ }^{1,3}$ Constantine I Vardavas ${ }^{1,4}$
}

\begin{abstract}
Background This study assessed the role of cigarette design and marketing characteristics in initial smoking, cigarette brand choice and the perception of reduced harm of cigarette brands among adults in the European Union in 2012.

Methods Data were from the Eurobarometer 385 (V.77.1) survey conducted in 2012 ( $n=26566)$. Multivariate logistic regression was used to assess associations between cigarette design/marketing features with aspects of initial smoking (among current and former smokers), cigarette brand choice and perception of reduced harm of cigarette brands (among current smokers; $p<0.05$ ).
\end{abstract}

Results Respondents aged $\geq 55$ years had lower OR than 15-24-year-olds of reporting initial smoking because of the presence of menthol flavour (adjusted OR $(A O R)=0.42 ; 95 \% \mathrm{Cl} 0.24$ to 0.72$)$ or a specific sweet, fruity or spicy flavour ( $A O R=0.38 ; 95 \% \mathrm{Cl} 0.20$ to 0.73 ). Females had higher $O R$ than males of reporting initial smoking because of the presence of menthol flavour (AOR=2.89; 95\% Cl 2.07 to 4.02). Furthermore, female smokers were more likely to choose a cigarette brand based on specific tastes such as menthol or spicy, fruity or sweet flavours ( $A O R=1.33 ; 95 \% \mathrm{Cl} 1.14$ to 1.56), or on the levels of tar, nicotine and carbon monoxide ( $A O R=1.30 ; 95 \% \mathrm{Cl} 1.11$ to 1.52).

Characteristics such as light-coloured packaging, the shape and size of cigarettes and the pack, the use of terms in the brand name such as 'silver' or 'blue' or descriptors such as 'natural' or 'organic' were all associated with perceptions of reduced harm among specific demographic groups.

Conclusions These findings call for a stronger regulation of tobacco ingredients, packaging features and other marketing strategies that may increase the attractiveness of tobacco products or promote perceptions of harm reduction.

\section{INTRODUCTION}

Tobacco use is the leading cause of premature morbidity and mortality in the European Union (EU), responsible for close to 700000 deaths each year. ${ }^{1}$ In recent years, tobacco control efforts in the EU have focused on youths as evidenced by the regulatory focus of the revised EU Tobacco Products Directive which was signed in 2014 and is proposed to go into effect by May $2016 .^{2}$ The directive notes that $70 \%$ of all adult smokers in the EU begin smoking by age 18 years, with about $94 \%$ starting before the age of 25 years. ${ }^{1}$ Hence, it is imperative to reduce youth smoking initiation, increase smoking cessation and prevent other unintended consequences from tobacco use.

The tobacco industry has done extensive research on the hedonic effects of cigarette smoking and has used several cigarette engineering features and marketing strategies to target consumers and potential consumers. $^{3-8}$ It is well acknowledged that sensory characteristics that maintain tobacco product appeal and ease of use are important in influencing smoking behaviour independent of the direct effects of nicotine. ${ }^{9}$ For example, the sensory effects of menthol, including its cooling, analgesic and soothing effects, alleviate the irritating and harsh effects of nicotine, thus increasing the ease of smoking experimentation among youths. ${ }^{10} 11$ Certain cigarette design and packaging characteristics could mislead consumers by suggesting benefits in terms of weight loss, sex appeal, economic class, social life or qualities such as femininity, elegance or masculinity. ${ }^{12}{ }^{13}$ In addition, visual elements of tobacco design or packaging, particularly colour, may be used by the tobacco industry to cue or amplify the perceived sensory reward from smoking, ${ }^{14} 15$ or to indirectly communicate a misleading message of reduced harm relative to other tobacco products. ${ }^{14}$ While the use of deceptive descriptors such as 'mild', 'light' and 'ultra-light' on tobacco products has been banned within the EU Tobacco Products Directive, stealthy cigarette packaging features may circumvent this prohibition. ${ }^{2}$

In view of ongoing tobacco control regulations across the $\mathrm{EU},{ }^{2}$ it is important to determine which elements of cigarette design and marketing in Europe are associated with initial smoking, increased product appeal and perception of reduced harm among smokers. A nuanced understanding of differences by age, gender and other subpopulation groups in receptivity to cigarette design and marketing features may help in formulating targeted tobacco control policies to prevent smoking experimentation and progression among vulnerable groups. Hence, this study assessed the role of cigarette design and marketing characteristics in initial smoking, cigarette brand choice and the perception of reduced harm of tobacco products among cigarette smokers in $27 \mathrm{EU}$ member states in 2012.

\section{METHODS}

\section{Data source}

Data were obtained from the Special Eurobarometer 385 (V.77.1) survey conducted by the European 
Commission between 25 February and 11 March 2012. In total, 26566 adults aged $\geq 15$ years from 27 member states in the EU were surveyed. In all member states, a multistage, random (probability) design was used to select respondents. All interviews were conducted face to face in people's homes and in the appropriate national language.

\section{Definitions}

Sociodemographic characteristics

All the 27 member states surveyed were categorised into four subregions using the United Nations' grouping: Western Europe (France, Belgium, Austria, Germany, the Netherlands and Luxembourg), Southern Europe (Greece, Italy, Malta, Portugal, Slovenia, Spain and the Republic of Cyprus), Northern Europe (Denmark, Ireland, the UK, Latvia, Lithuania, Finland, Sweden and Estonia) and Eastern Europe (Czech Republic, Slovakia, Hungary, Poland, Bulgaria and Romania).

Data were also collected on respondents' age (15-24; 25-39; $40-54$ or $\geq 55$ years), sex (male or female), area of residence/ urbanicity (rural or urban) and socioeconomic status (SES), which was measured with a surrogate indicator-financial difficulties during the past year. This was assessed with the question "During the last twelve months, would you say you had difficulties to pay your bills at the end of the month...?" Response options included: 'Most of the time' (lower SES), 'From time to time' (middle SES) or 'Almost never/never' (upper SES).

\section{Current tobacco smoking status}

Current cigarette smokers $(n=6896)$ were defined as respondents who indicated smoking 'boxed cigarettes' (ie, factory manufactured cigarettes) 'everyday', 'weekly', 'monthly' or 'less than monthly'. We restricted the analyses to users of factory manufactured cigarettes because most of the product design and marketing characteristics assessed in the study were focused on cigarettes rather than other types of tobacco products such as pipes, hand-rolled cigarettes or cigars. Former smokers $(n=5782)$ were respondents who indicated that they used to smoke but had stopped smoking at the time of the survey. The age of initiation of regular smoking was assessed with the question "How old were you when you started smoking on a regular basis, i.e. at least once a week?" Categorical response options (years) were '<15', '15-18'; '19-25' or ' $>25$ ' years of age.

Effect of cigarette design and marketing elements: initial smoking Current and former cigarette smokers were asked "Among the following, what were the most significant elements that made you start smoking?" Participants were able to select up to three response options which could include any of the following: 'You liked the packaging of the cigarettes'; 'You liked the taste or smell of tobacco'; 'You liked menthol cigarettes'; 'You liked cigarettes with a specific sweet, fruity or spicy flavor'; or 'Cigarettes were affordable'. In addition to these cigarettespecific characteristics, the influences of peer and parental tobacco use on initial smoking were also assessed in the response options.

Effect of cigarette design and marketing elements: cigarette brand choice

Current cigarette smokers were asked "How important is each of the following factors in your choice of brand of cigarettes?" Six attributes were assessed and respondents could select any that applied. The attributes assessed were 'the price'; 'the packaging'; 'the taste of tobacco'; 'the specific brand'; 'the specific tastes such as menthol, spicy, fruity or sweet' or 'the levels of tar, nicotine and carbon monoxide (TNCO)'. Categorical response options for each of the assessed attributes included the following four from which respondents could select only one option: 'Very important', 'Fairly important', 'Not very important' or 'Not at all important'. For further analyses, these response options were dichotomised, with responses of 'Very important' or 'Fairly important' categorised as a positive indication that the measured variable was important in determining cigarette brand choice, whereas a response of 'Not very important' or 'Not at all important' was treated as a dissenting response. Respondents who indicated 'Don't know' were excluded from the analyses.

\section{Effect of cigarette design and marketing elements:} reduced harm perception

Current cigarette smokers were asked "Which of the following characteristics do you consider indicate that a cigarette brand is less harmful than others?" Multiple options were allowed and assessed attributes were 'Menthol flavor'; 'Other taste/flavor, such as a spicy, sweet or fruity flavor'; 'The shape and size of a cigarette, e.g. slim cigarettes'; 'The tar or nicotine levels indicated on pack'; 'The light color of the pack'; 'Specific terms in the brand's name, such as "silver" or "blue"; 'Cigarettes without additives'; 'Cigarettes labeled as "organic" or "natural"; or 'The shape or texture of the pack (e.g. slim pack or soft pack)'.

\section{Statistical analyses}

Since descriptive country-specific estimates have already been published in the official Eurobarometer report, ${ }^{1}$ our research focused mainly on overall EU-wide descriptive statistics (\%) and multivariate analyses. Multiple logistic regression models were fitted to assess subgroup differences in receptivity to various cigarette design and marketing characteristics related to (1) initial smoking (among current and former cigarette smokers), (2) cigarette brand choice (among current cigarette smokers), and (3) the perception of reduced harm (among current cigarette smokers). The regression analyses controlled for sex, age, the EU region, SES, residence type and age at initiation of regular smoking. All data were weighted to account for the complex survey design, and all analyses were performed with Stata V.12.0.

\section{RESULTS}

Baseline results provided by the Eurobarometer 385 survey reported $50.6 \%$ of respondents as never smokers, $27.9 \%$ as current smokers and $21.3 \%$ as ex-smokers, while additional Eurobarometer 385 descriptive results are available through the official report. ${ }^{1}$

\section{Effect of cigarette design and marketing elements: initial smoking}

Overall, the factors most frequently cited as being important in relation to initial smoking among current and former cigarette smokers in the EU were smoking by friends (79.4\%) and by parents $(20.6 \%)$. However, with regard to the role of cigarette design and marketing elements, the following factors were indicated by current and former cigarette smokers as being important to their initial smoking: the taste or smell of the tobacco (18.9\%), the affordable price of cigarettes (12.2\%), the menthol flavour (3.2\%), the tobacco packaging $(2.8 \%)$ and a specific sweet, fruity or spicy flavour in cigarettes (1.4\%).

Females had higher OR than males of reporting initial smoking because of the menthol flavour (adjusted OR (AOR) 
$=2.89 ; 95 \%$ CI 2.07 to 4.02 ), but had lower OR of reporting initial smoking because of either the taste or smell of tobacco $(\mathrm{AOR}=0.79 ; 95 \% \mathrm{CI} 0.69$ to 0.91$)$, or the affordable price of cigarettes $(\mathrm{AOR}=0.72 ; 95 \%$ CI 0.61 to 0.86 ; table 1$)$. Respondents living in rural areas had lower OR than those living in urban areas of reporting initial smoking because of the menthol flavour $(\mathrm{AOR}=0.65 ; 95 \% \quad \mathrm{CI} \quad 0.48$ to 0.89 ). Respondents in Southern Europe had lower OR than those in Western Europe of reporting initial smoking because of the menthol flavour $(\mathrm{AOR}=0.37 ; 95 \% \mathrm{CI} 0.21$ to 0.64$)$. Also, respondents in Eastern Europe had lower OR than those in Western Europe of reporting initial smoking because of a specific sweet, fruity or spicy flavour (AOR $=0.59 ; 95 \%$ CI 0.35 to 0.98 ), but higher OR of reporting initial smoking because of the packaging of cigarettes (AOR $=1.60 ; 95 \%$ CI 1.08 to 2.37). Respondents aged $\geq 55$ years had lower OR than 1524-year-olds of reporting initial smoking because of the menthol flavour (AOR $=0.42 ; 95 \% \mathrm{CI} 0.24$ to 0.72 ) or the presence of a specific sweet, fruity or spicy flavour $(\mathrm{AOR}=0.38$; 95\% CI 0.20 to 0.73 ).

Individuals from the upper SES had lower OR than those from the lower SES of reporting initial smoking because of the affordability of cigarettes (AOR $=0.62 ; 95 \%$ CI 0.48 to 0.79 ). The OR of reporting initial smoking because of the affordable price of cigarettes were also significantly lower among smokers in Southern Europe $(\mathrm{AOR}=0.40 ; 95 \%$ CI 0.28 to 0.51$)$ and Northern Europe (AOR $=0.67 ; 95 \%$ CI 0.52 to 0.86 ) when compared with Western Europe. Furthermore, the OR of reporting initial smoking because of the affordable price of cigarettes increased with increasing age and were 1.60, 1.87 and 2.47 among the $25-39,40-54$ and $\geq 55$-year-olds, respectively, when compared with the 15-24-year-olds (all p<0.05). Respondents who started smoking at an older age ( $>25$ years) had lower OR of reporting affordable price of cigarettes as influencing their initial smoking compared with those who started smoking at age $<15$ years $(\mathrm{AOR}=0.49 ; 95 \% \mathrm{CI} 0.30$ to $0.83)$.

\section{Effect of cigarette design and marketing elements: cigarette brand choice}

The following characteristics were rated by current smokers as being important in their cigarette brand choice: the taste of the tobacco $(88.5 \%)$; the price $(75 \%)$; the specific brand name (69.2\%); TNCO levels (52.3\%); a specific sweet, menthol, fruity or spicy flavour (33\%), and the packaging (24\%). After adjustment, female current smokers had higher OR than males of choosing a cigarette brand based on a specific sweet, menthol, fruity or spicy flavour $(\mathrm{AOR}=1.33 ; 95 \% \mathrm{CI} 1.14$ to 1.56$)$, or TNCO levels $(\mathrm{AOR}=1.30 ; 95 \%$ CI 1.11 to 1.52 ; table 2$)$. Current smokers from the upper SES had higher OR than those from the lower SES of choosing cigarettes based on the brand name $(\mathrm{AOR}=1.77 ; 95 \% \mathrm{CI} 1.41$ to 2.23$)$, or on a specific sweet, menthol, fruity or spicy flavour $(\mathrm{AOR}=1.36$; 95\% CI 1.09 to 1.72), but lower OR of choosing cigarettes based on the price $(\mathrm{AOR}=0.38 ; 95 \% \mathrm{CI} 0.29$ to 0.50$)$. Current smokers in rural areas had lower OR than those in urban areas of choosing

Table 1 The importance of cigarette design and marketing elements on initial smoking among current and former cigarette smokers, Eurobarometer 385 (V.77.1) survey, February-March 2012 ( $n=12$ 678)

\begin{tabular}{|c|c|c|c|c|c|}
\hline Characteristics & $\begin{array}{l}\text { Taste or smell } \\
\text { of tobacco } \\
\text { AOR }(95 \% \mathrm{Cl})\end{array}$ & $\begin{array}{l}\text { Menthol flavour } \\
\text { AOR }(95 \% \mathrm{Cl})\end{array}$ & $\begin{array}{l}\text { A specific sweet, fruity } \\
\text { or spicy flavour } \\
\text { AOR }(95 \% \mathrm{Cl})\end{array}$ & $\begin{array}{l}\text { Packaging of } \\
\text { cigarettes } \\
\text { AOR }(95 \% \mathrm{CI})\end{array}$ & $\begin{array}{l}\text { Affordable price } \\
\text { of cigarettes } \\
\text { AOR }(95 \% \mathrm{CI})\end{array}$ \\
\hline \multicolumn{6}{|l|}{ Sex } \\
\hline \multicolumn{6}{|l|}{ Male (referent) } \\
\hline Female & $0.79(0.69 \text { to } 0.91)^{*}$ & $2.89(2.07 \text { to } 4.02)^{*}$ & $1.00(0.62$ to 1.59$)$ & $0.78(0.57$ to 1.06$)$ & $0.72(0.61 \text { to } 0.86)^{*}$ \\
\hline \multicolumn{6}{|l|}{ Socioeconomic status } \\
\hline \multicolumn{6}{|l|}{ Lower (referent) } \\
\hline Middle & $1.05(0.85$ to 1.31$)$ & $0.79(0.45$ to 1.38$)$ & $1.12(0.53$ to 2.39$)$ & $1.01(0.64$ to 1.59$)$ & $0.95(0.73$ to 1.23$)$ \\
\hline Upper & $0.86(0.70$ to 1.06$)$ & $1.19(0.71$ to 1.99$)$ & $1.45(0.72$ to 2.89$)$ & $0.83(0.54$ to 1.28$)$ & $0.62(0.48 \text { to } 0.79)^{*}$ \\
\hline \multicolumn{6}{|l|}{ Type of residence } \\
\hline \multicolumn{6}{|l|}{ Urban (referent) } \\
\hline Rural & $0.88(0.77$ to 1.02$)$ & $0.65(0.48 \text { to } 0.89)^{*}$ & $0.84(0.51$ to 1.39$)$ & $1.10(0.80$ to 1.51$)$ & $1.00(0.85$ to 1.19$)$ \\
\hline \multicolumn{6}{|l|}{ Region in the EU } \\
\hline \multicolumn{6}{|c|}{ Western Europe (referent) } \\
\hline Southern Europe & $1.28(1.06 \text { to } 1.54)^{*}$ & $0.37(0.21 \text { to } 0.64)^{*}$ & $0.60(0.31$ to 1.15$)$ & 1.35 (0.88 to 2.06$)$ & $0.40(0.28 \text { to } 0.51)^{*}$ \\
\hline Northern Europe & $0.55(0.44$ to 0.68$)$ & $0.86(0.57$ to 1.30$)$ & $0.50(0.25$ to 1.00$)$ & $0.60(0.36$ to 1.01$)$ & $0.67(0.52 \text { to } 0.86)^{*}$ \\
\hline Eastern Europe & $1.10(0.93$ to 1.30$)$ & $1.04(0.71$ to 1.52$)$ & $0.59(0.35 \text { to } 0.98)^{*}$ & $1.60(1.08 \text { to } 2.37)^{*}$ & $1.03(0.86$ to 1.24$)$ \\
\hline \multicolumn{6}{|l|}{ Age, years } \\
\hline \multicolumn{6}{|l|}{ 15-24 (referent) } \\
\hline 25-39 & $0.95(0.73$ to 1.24$)$ & $0.66(0.38$ to 1.13$)$ & $0.45(0.24 \text { to } 0.83)^{*}$ & $1.06(0.61$ to 1.85$)$ & $1.60(1.04 \text { to } 2.46)^{*}$ \\
\hline $40-54$ & $0.91(0.70$ to 1.18$)$ & 0.64 (0.37 to 1.08$)$ & $0.49(0.24$ to 1.02$)$ & 1.39 (0.80 to 2.42$)$ & $1.87(1.22 \text { to } 2.86)^{*}$ \\
\hline$\geq 55$ & $1.04(0.80$ to 1.34$)$ & $0.42(0.24 \text { to } 0.72)^{*}$ & $0.38(0.20 \text { to } 0.73)^{*}$ & $1.13(0.65$ to 1.98$)$ & $2.47(1.62 \text { to } 3.76)^{*}$ \\
\hline \multicolumn{6}{|c|}{ Age at initiation of regular smoking, years } \\
\hline \multicolumn{6}{|c|}{$<15$} \\
\hline $15-18$ & $1.15(0.94$ to 1.41$)$ & $0.91(0.56$ to 1.48$)$ & $1.11(0.60$ to 2.04$)$ & $1.14(0.71$ to 1.83$)$ & $1.02(0.80$ to 1.32$)$ \\
\hline $19-25$ & $1.15(0.91$ to 1.45$)$ & $1.52(0.91$ to 2.54$)$ & $0.93(0.47$ to 1.83$)$ & $0.95(0.56$ to 1.60$)$ & $1.09(0.83$ to 1.43$)$ \\
\hline$>25$ & $0.94(0.64$ to 1.39$)$ & 1.29 (0.57 to 2.89$)$ & $1.43(0.48$ to 4.20$)$ & $0.87(0.32$ to 2.40$)$ & $0.49(0.30 \text { to } 0.83)^{*}$ \\
\hline
\end{tabular}


Table 2 The importance of cigarette design and marketing elements in cigarette brand choice among current cigarette smokers, Eurobarometer 385 (V.77.1) survey, February-March 2012 $(n=6896)$

\begin{tabular}{|c|c|c|c|c|c|c|}
\hline Characteristics & $\begin{array}{l}\text { Taste of tobacco } \\
\text { AOR }(95 \% \mathrm{Cl})\end{array}$ & $\begin{array}{l}\text { Specific tastes e.g., a } \\
\text { sweet, menthol, } \\
\text { fruity or spicy flavour } \\
\text { AOR }(95 \% \mathrm{Cl})\end{array}$ & $\begin{array}{l}\text { Brand name } \\
\text { AOR }(95 \% \mathrm{Cl})\end{array}$ & $\begin{array}{l}\text { Tar, nicotine and } \\
\text { carbon monoxide } \\
\text { levels } \\
\text { AOR }(95 \% \mathrm{Cl})\end{array}$ & $\begin{array}{l}\text { Packaging of } \\
\text { cigarettes } \\
\text { AOR }(95 \% \mathrm{Cl})\end{array}$ & $\begin{array}{l}\text { Price of cigarettes } \\
\text { AOR }(95 \% \mathrm{Cl})\end{array}$ \\
\hline \multicolumn{7}{|l|}{ Sex } \\
\hline \multicolumn{7}{|l|}{ Male (referent) } \\
\hline Female & $1.16(0.91$ to 1.46$)$ & $1.33(1.14 \text { to } 1.56)^{*}$ & $1.15(0.97$ to 1.35$)$ & $1.30(1.11 \text { to } 1.52)^{*}$ & $1.13(0.95$ to 1.34$)$ & $0.99(0.82$ to 1.18$)$ \\
\hline \multicolumn{7}{|l|}{ Socioeconomic status } \\
\hline \multicolumn{7}{|l|}{ Lower (referent) } \\
\hline Middle & $1.57(1.11 \text { to } 2.23)^{*}$ & $1.21(0.97$ to 1.54$)$ & $1.76(1.39 \text { to } 2.26)^{*}$ & $1.06(0.85$ to 1.32$)$ & $1.24(0.98$ to 1.58$)$ & $0.82(0.60$ to 1.12$)$ \\
\hline Upper & $1.26(0.91$ to 1.74$)$ & $1.36(1.09 \text { to } 1.72)^{*}$ & $1.77(1.41 \text { to } 2.23)^{*}$ & $0.89(0.72$ to 1.11$)$ & $1.17(0.92$ to 1.49$)$ & $0.38(0.29 \text { to } 0.50)^{*}$ \\
\hline \multicolumn{7}{|l|}{ Type of residence } \\
\hline \multicolumn{7}{|l|}{ Urban (referent) } \\
\hline Rural & $0.67(0.53 \text { to } 0.86)^{*}$ & $0.85(0.72$ to 1.00$)$ & $0.79(0.66 \text { to } 0.94)^{*}$ & $0.65(0.55 \text { to } 0.77)^{*}$ & $0.81(0.67 \text { to } 0.97)^{*}$ & $0.95(0.78$ to 1.15$)$ \\
\hline \multicolumn{7}{|l|}{ Region in the EU } \\
\hline \multicolumn{7}{|c|}{ Western Europe (referent) } \\
\hline Southern Europe & $1.58(1.11 \text { to } 2.23)^{*}$ & $0.70(0.56 \text { to } 0.88)^{*}$ & $1.99(1.58 \text { to } 2.50)^{*}$ & $2.33(1.88 \text { to } 2.88)^{*}$ & $3.35(2.58 \text { to } 4.36)^{*}$ & $1.97(1.55 \text { to } 2.51)^{*}$ \\
\hline Northern Europe & $0.59(0.42 \text { to } 0.84)^{*}$ & $0.83(0.65$ to 1.07$)$ & $1.01(0.79$ to 1.31$)$ & $0.98(0.77$ to 1.25$)$ & $1.20(0.87$ to 1.65$)$ & $1.31(1.01 \text { to } 1.70)^{*}$ \\
\hline Eastern Europe & $0.96(0.71$ to 1.30$)$ & $1.51(1.24 \text { to } 1.85)^{*}$ & $1.50(1.22 \text { to } 1.86)^{*}$ & $2.36(1.92 \text { to } 2.89)^{*}$ & $3.56(2.79 \text { to } 4.56)^{*}$ & $3.13(2.46 \text { to } 3.98)^{*}$ \\
\hline \multicolumn{7}{|l|}{ Age, years } \\
\hline \multicolumn{7}{|l|}{ 15-24 (referent) } \\
\hline $25-39$ & $1.25(0.85$ to 1.82$)$ & $1.04(0.80$ to 1.35$)$ & $1.10(0.84$ to 1.44$)$ & 0.99 (0.76 to 1.28$)$ & $1.12(0.84$ to 1.50$)$ & $0.88(0.64$ to 1.18$)$ \\
\hline $40-54$ & $1.12(0.75$ to 1.66$)$ & $1.11(0.84$ to 1.45$)$ & $1.10(0.84$ to 1.45$)$ & $1.06(0.82$ to 1.39$)$ & $0.97(0.72$ to 1.31$)$ & $0.93(0.67$ to 1.27$)$ \\
\hline$\geq 55$ & $1.08(0.73$ to 1.60$)$ & $1.03(0.77$ to 1.37$)$ & $1.60(1.20 \text { to } 2.14)^{*}$ & $1.27(0.96$ to 1.67$)$ & $0.90(0.66$ to 1.24$)$ & $1.04(0.75$ to 1.43$)$ \\
\hline \multicolumn{7}{|c|}{ Age at initiation of regular smoking, years } \\
\hline \multicolumn{7}{|c|}{$<15$} \\
\hline $15-18$ & $1.30(0.94$ to 1.81$)$ & $1.24(0.98$ to 1.57$)$ & $1.44(1.14 \text { to } 1.81)^{*}$ & 1.25 (1.00 to 1.56$)$ & $1.32(1.01 \text { to } 1.72)^{*}$ & 1.11 (0.85 to 1.45$)$ \\
\hline $19-25$ & 0.91 (0.62 to 1.32$)$ & $1.09(0.84$ to 1.43$)$ & $1.43(1.10$ to 1.88$)$ & $1.46(1.13 \text { to } 1.88)^{*}$ & $1.49(1.10 \text { to } 2.01)^{*}$ & $0.85(0.63$ to 1.15$)$ \\
\hline$>25$ & 0.65 (0.36 to 1.17$)$ & 1.02 (0.66 to 1.58 ) & 1.15 (0.73 to 1.80$)$ & $1.69(1.11 \text { to } 2.59)^{*}$ & 1.64 (0.99 to 2.70$)$ & 0.91 (0.56 to 1.47$)$ \\
\hline
\end{tabular}


cigarettes based on the appearance of the packaging $(\mathrm{AOR}=0.81$; 95\% CI 0.67 to 0.97 ), the brand name (AOR $=0.79 ; 95 \%$ CI 0.66 to 0.94$)$, the taste of the tobacco $(\mathrm{AOR}=0.67 ; 95 \% \mathrm{CI} 0.53$ to 0.86 ) or TNCO levels ( $\mathrm{AOR}=0.65 ; 95 \% \mathrm{CI} 0.55$ to 0.77 ).

The OR of reporting price as a determinant of cigarette brand choice were higher among current smokers in Southern Europe $(\mathrm{AOR}=1.97)$, Northern Europe $(\mathrm{AOR}=1.31)$ and Eastern Europe $(\mathrm{AOR}=3.13)$ compared with Western Europe (all $\mathrm{p}<0.05)$. In addition, current smokers in Eastern Europe had higher OR than those in Western Europe of rating the following factors as being important in their cigarette brand choice: a specific sweet, menthol, fruity or spicy flavour $(\mathrm{AOR}=1.51 ; 95 \% \quad \mathrm{CI} 1.24$ to 1.85$)$, the brand name $(\mathrm{AOR}=1.50 ; 95 \%$ CI 1.22 to 1.86$)$, TNCO levels $(\mathrm{AOR}=2.36$; 95\% CI 1.92 to 2.89$)$ and the cigarette packaging $(\mathrm{AOR}=3.56$; 95\% CI 2.79 to 4.56 ).

Current smokers aged $\geq 55$ years were more likely than 15 24-year-olds to be conscious of the brand name when choosing cigarettes (AOR $=1.60 ; 95 \%$ CI 1.20 to 2.14). Similarly, current smokers who started smoking at age 15-18 years had higher OR than those who started smoking at age $<15$ years of reporting that the brand name ( $\mathrm{AOR}=1.44 ; 95 \% \mathrm{CI} 1.14$ to 1.81$)$ or the cigarette packaging ( $\mathrm{AOR}=1.32 ; 95 \% \mathrm{CI} 1.01$ to 1.72 ) was important in their cigarette brand choice. The OR of reporting TNCO levels as being important in cigarette brand choice were significantly higher among current smokers who started smoking at ages $19-25(\mathrm{AOR}=1.46 ; 95 \%$ CI 1.13 to 1.88$)$ or $>25$ years $(\mathrm{AOR}=1.69 ; 95 \%$ CI 1.11 to 2.59$)$ compared with those who started smoking at age $<15$ years.

\section{Effect of cigarette design and marketing elements: reduced harm perception}

The following cigarette design characteristics were perceived by current smokers to be indicative of reduced harm of a cigarette brand: TNCO levels on the pack (43.8\%); cigarettes without additives (13\%); specific terms in the brand name such as 'silver' or 'blue' (10.3\%); the light colour of the pack (8.5\%); cigarettes labelled as 'organic' or 'natural' (7.9\%); the shape and size of cigarettes, for example, slim cigarettes (6.3\%); the presence of menthol (5.2\%); a specific sweet, fruity or spicy flavour $(2.6 \%)$; and the shape or texture of the pack (eg, slim pack or soft pack; $1.6 \%)$.

The OR of perceiving menthol cigarettes as being less harmful were $0.57,0.52$ and 0.40 lower among current smokers aged $25-39,40-54$ and $\geq 55$, respectively, when compared with those aged $15-24$ years $($ all $\mathrm{p}<0.05)$. Similarly, current smokers aged $25-39,40-54$ and $\geq 55$ had lower OR of perceiving cigarettes labelled as 'organic'/'natural' $(\mathrm{AOR}=0.66,0.48$ and 0.53 , respectively), or the shape and size of a cigarette $(\mathrm{AOR}=0.43$, 0.48 and 0.49 , respectively) as being less harmful when compared with smokers aged $15-24$ years (all $\mathrm{p}<0.05$ ). Furthermore, respondents aged 25-39 years had significantly lower OR than 15-24-year-olds of perceiving TNCO levels as an indicator of reduced harm (AOR $=0.73 ; 95 \% \mathrm{CI} 0.57$ to 0.93 ).

The OR of perceiving cigarettes with terms such as 'silver' or 'blue' in their brand names as being less harmful were higher among the upper SES current smokers compared with the lower SES current smokers (AOR $=1.40 ; 95 \%$ CI 1.02 to 1.92). On the other hand, the upper SES smokers had lower OR than the lower SES smokers of perceiving light-coloured cigarette packs $(\mathrm{AOR}=0.71 ; 95 \% \mathrm{CI} 0.51$ to 0.98$)$ or cigarettes labelled as 'organic' or 'natural' (AOR $=0.54 ; 95 \% \mathrm{CI} 0.37$ to 0.77 ) as being indicative of less harm (table 3 ).
Current smokers in Eastern Europe had higher OR than those in Western Europe of perceiving several cigarette design and marketing features as being indicative of less harm, including light-coloured cigarette packs ( $\mathrm{AOR}=2.19$; 95\% CI 1.62 to 2.96), sweet, fruity or spicy flavour ( $\mathrm{AOR}=1.75 ; 95 \% \mathrm{CI} 1.01$ to 3.03); the shape and size of cigarettes (AOR $=2.77 ; 95 \% \mathrm{CI}$ 1.94 to 3.95); the shape or texture of the tobacco pack $(\mathrm{AOR}=2.25 ; 95 \% \mathrm{CI} 1.26$ to 4.05$)$; specific terms in the brand name such as 'silver' or 'blue' ( $\mathrm{AOR}=1.52$; $95 \%$ CI 1.14 to 2.02) and TNCO levels indicated on the pack $(\mathrm{AOR}=1.39$; $95 \%$ CI 1.14 to 1.68 ).

\section{DISCUSSION}

This study highlighted several elements of cigarette design, manufacture and marketing that were significantly associated with increased product appeal and reduced harm perception among several population groups. These elements fell into three main groups: (1) Modifications involving cigarette stick characteristics (eg, length or diameter) or tobacco ingredient formulation (eg, tobacco blend) - which are generally the most important determinants of the chemosensory properties of tobacco smoke including taste, irritation, strength and impact. $^{7} 1617$ (2) Additive enhancements such as the use of characterising flavours to increase smoking appeal/attractiveness, particularly among naïve smokers. ${ }^{18}{ }^{19}$ (3) Marketing features, including tobacco pricing, as well as a plethora of tobacco packaging elements such as colour schemes and brand descriptors that could subtly convey false messages of reduced risk or heightened perception of reward from tobacco use. ${ }^{5}$ Most of the characteristics assessed in our study fell under this category including "Cigarettes labeled as "organic" or "natural", "The light color of the pack', or 'Specific terms in the brand's name, such as "silver" or "blue".

Colour is a particularly powerful instrument in tobacco marketing because of its profound effect on emotions and memory. ${ }^{14}$ For example, red is an emotionally vivid and intense colour, often used by the tobacco industry to suggest a rich, bold or strong taste (eg, high tar brands). Green and blue are associated with a calming effect and are commonly used in packaging of mentholated brands to suggest a cooling or soothing effect. White-often connoted with light and cleanliness-is commonly used to package low tar brands. Indeed, internal tobacco industry documents have shown that sensory perceptions of cigarettes can be manipulated simply by changing the colour or shade of colour on a pack. ${ }^{14}$ For example, package testing on Camel filter cigarettes showed that increasing the amount of white space on the pack and lightening brown colours reduced the smokers' perception of the cigarette strength. ${ }^{14}$ Such subterfuge packaging strategies could instil consumer perceptions that are inconsistent with the actual emission yields. ${ }^{20}$ These findings call for stronger measures to regulate tobacco packaging.

The recent EU-wide adoption of pictorial warnings on tobacco products as specified within the Tobacco Products Directive $(65 \%$ of the front and the back as well as $50 \%$ of the sides of cigarette packs) is a major stride in tobacco package regulation, and might pave the way for adoption of plain packaging in the future. During 2012, 57\% of all EU adults supported plain packaging, with significantly higher support noted in EU member states that had already implemented pictorial warnings. ${ }^{121}$ As all EU member states move towards implementing pictorial warnings by $2016,{ }^{2}$ enhanced and sustained tobacco surveillance will be needed to monitor changes in tobacco initiation and cessation among youths going forward. 
Table 3 The importance of cigarette design and marketing elements on perception of reduced harm among current cigarette smokers, Eurobarometer 385 (V.77.1) survey, February-March 2012 $(n=6896)$

\begin{tabular}{|c|c|c|c|c|c|c|c|c|c|}
\hline Characteristic & $\begin{array}{l}\text { Menthol flavour } \\
\text { AOR }(95 \% \mathrm{Cl})\end{array}$ & $\begin{array}{l}\text { Other tastes/ } \\
\text { flavours, such as a } \\
\text { spicy, sweet or } \\
\text { fruity flavour } \\
\text { AOR }(95 \% \mathrm{Cl})\end{array}$ & $\begin{array}{l}\text { The shape and } \\
\text { size of a cigarette } \\
\text { AOR }(95 \% \mathrm{Cl})\end{array}$ & $\begin{array}{l}\text { The shape or } \\
\text { texture of the } \\
\text { pack } \\
\text { AOR }(95 \% \mathrm{Cl})\end{array}$ & $\begin{array}{l}\text { The light colour } \\
\text { of the pack } \\
\text { AOR }(95 \% \mathrm{Cl})\end{array}$ & $\begin{array}{l}\text { Cigarettes } \\
\text { labelled as } \\
\text { 'organic' or } \\
\text { 'natural' } \\
\text { AOR }(95 \% \mathrm{Cl})\end{array}$ & $\begin{array}{l}\text { Specific terms in } \\
\text { the brand's name, } \\
\text { such as 'silver' or } \\
\text { 'blue' } \\
\text { AOR }(95 \% \mathrm{Cl})\end{array}$ & $\begin{array}{l}\text { Tar, nicotine and } \\
\text { carbon monoxide } \\
\text { levels } \\
\text { AOR }(95 \% \mathrm{Cl})\end{array}$ & $\begin{array}{l}\text { Cigarettes } \\
\text { without additives } \\
\text { AOR }(95 \% \mathrm{Cl})\end{array}$ \\
\hline \multicolumn{10}{|l|}{ Sex } \\
\hline \multicolumn{10}{|l|}{ Male (referent) } \\
\hline Female & 1.27 (0.90 to 1.77$)$ & 0.81 (0.51 to 1.28 ) & 1.08 (0.81 to 1.43 ) & 1.38 (0.84 to 2.27 ) & 1.21 (0.95 to 1.54$)$ & $1.14(0.87$ to 1.50$)$ & $0.78(0.62 \text { to } 0.99)^{*}$ & $1.00(0.86$ to 1.16$)$ & $0.92(0.74$ to 1.16$)$ \\
\hline \multicolumn{10}{|l|}{ Socioeconomic status } \\
\hline \multicolumn{10}{|l|}{ Lower (referent) } \\
\hline Middle & 0.95 (0.58 to 1.55$)$ & $1.02(0.53$ to 1.96$)$ & 0.89 (0.59 to 1.32$)$ & 0.70 (0.33 to 1.47$)$ & $0.76(0.55$ to 1.06$)$ & $0.71(0.49$ to 1.02$)$ & $1.09(0.78$ to 1.51$)$ & 1.08 (0.87 to 1.35$)$ & 0.99 (0.72 to 1.36$)$ \\
\hline Upper & $0.99(0.62$ to 1.57$)$ & 0.87 (0.46 to 1.66$)$ & $0.76(0.52$ to 1.11$)$ & 0.68 (0.34 to 1.38$)$ & $0.71(0.51 \text { to } 0.98)^{*}$ & $0.54(0.37 \text { to } 0.77)^{*}$ & $1.40(1.02 \text { to } 1.92)^{*}$ & 0.94 (0.76 to 1.16$)$ & 0.77 (0.56 to 1.05$)$ \\
\hline \multicolumn{10}{|l|}{ Type of residence } \\
\hline \multicolumn{10}{|l|}{ Rural } \\
\hline \multicolumn{10}{|c|}{ Region in the EU } \\
\hline \multicolumn{10}{|c|}{ Western Europe (referent) } \\
\hline Southern Europe & $0.36(0.20 \text { to } 0.67)^{*}$ & $0.58(0.28$ to 1.22$)$ & $0.62(0.38$ to 1.02$)$ & $0.49(0.20$ to 1.25$)$ & 0.69 (0.46 to 1.03$)$ & $1.05(0.72$ to 1.51$)$ & 0.97 (0.69 to 1.38$)$ & $1.00(0.81$ to 1.23$)$ & $0.55(0.41 \text { to } 0.73)^{*}$ \\
\hline Northern Europe & $2.09(1.31 \text { to } 3.33)^{*}$ & 0.62 (0.29 to 1.32$)$ & $0.41(0.21 \text { to } 0.81)^{*}$ & 0.86 (0.32 to 2.34$)$ & 0.77 (0.51 to 1.18 ) & 0.77 (0.47 to 1.26$)$ & $0.43(0.28 \text { to } 0.66)^{*}$ & $0.90(0.71$ to 1.15$)$ & $0.27(0.19 \text { to } 0.40)^{*}$ \\
\hline Eastern Europe & $1.43(0.94$ to 2.17$)$ & $1.75(1.01 \text { to } 3.03)^{*}$ & $2.77(1.94 \text { to } 3.95)^{*}$ & $2.25(1.26 \text { to } 4.05)^{*}$ & $2.19(1.62 \text { to } 2.96)^{*}$ & 0.94 (0.67 to 1.32 ) & $1.52(1.14 \text { to } 2.02)^{*}$ & $1.39(1.14 \text { to } 1.68)^{*}$ & $0.41(0.31 \text { to } 0.54)^{*}$ \\
\hline \multicolumn{10}{|l|}{ Age, years } \\
\hline \multicolumn{10}{|l|}{ 15-24 (referent) } \\
\hline $25-39$ & $0.57(0.35 \text { to } 0.94)^{*}$ & $0.80(0.41$ to 1.53$)$ & $0.43(0.28 \text { to } 0.66)^{*}$ & 1.21 (0.54 to 2.68$)$ & 0.97 (0.65 to 1.45$)$ & $0.66(0.45 \text { to } 0.98)^{*}$ & 0.79 (0.54 to 1.15$)$ & $0.73(0.57 \text { to } 0.93)^{*}$ & 0.95 (0.66 to 1.35$)$ \\
\hline $40-54$ & $0.52(0.31 \text { to } 0.88)^{*}$ & 0.56 (0.27 to 1.17$)$ & $0.48(0.29 \text { to } 0.78)^{*}$ & 1.59 (0.77 to 3.28$)$ & 1.14 (0.75 to 1.73$)$ & $0.48(0.33 \text { to } 0.72)^{*}$ & 0.91 (0.61 to 1.34 ) & 0.84 (0.65 to 1.08$)$ & 0.77 (0.52 to 1.12$)$ \\
\hline$\geq 55$ & $0.40(0.22 \text { to } 0.71)^{*}$ & 0.65 (0.29 to 1.44$)$ & $0.49(0.31 \text { to } 0.76)^{*}$ & 2.03 (0.95 to 4.34$)$ & 0.97 (0.62 to 1.51$)$ & $0.53(0.34 \text { to } 0.83)^{*}$ & 0.69 (0.45 to 1.06$)$ & 0.81 (0.62 to 1.05 ) & 0.76 (0.52 to 1.13 ) \\
\hline \multicolumn{10}{|c|}{ Age at initiation of regular smoking, years } \\
\hline $15-18$ & 1.45 (0.87 to 2.38$)$ & 0.75 (0.40 to 1.43$)$ & 1.01 (0.60 to 1.70$)$ & 0.95 (0.41 to 2.21$)$ & $1.02(0.71$ to 1.48$)$ & $1.06(0.71$ to 1.59$)$ & 1.26 (0.87 to 1.82$)$ & 1.11 (0.89 to 1.39$)$ & 1.32 (0.96 to 1.82$)$ \\
\hline $19-25$ & $2.12(1.19 \text { to } 3.77)^{*}$ & 0.63 (0.31 to 1.27 ) & 1.07 (0.62 to 1.85 ) & 0.97 (0.38 to 2.48 ) & 0.75 (0.49 to 1.15$)$ & 1.39 (0.88 to 2.18 ) & 0.83 (0.54 to 1.27$)$ & 1.11 (0.87 to 1.43 ) & 1.30 (0.89 to 1.89 ) \\
\hline$>25$ & 4.56 (2.09 to 9.95$)^{*}$ & $1.14(0.35$ to 3.69$)$ & 1.04 (0.46 to 2.36$)$ & $1.16(0.26$ to 5.26$)$ & 0.74 (0.42 to 1.32$)$ & 0.79 (0.31 to 1.98$)$ & $1.16(0.62$ to 2.18$)$ & 0.97 (0.64 to 1.45$)$ & $1.18(0.62$ to 2.25$)$ \\
\hline
\end{tabular}


Such translational science will be critical in increasing public support for plain packaging within the EU.

The new European Commission Tobacco Products Directive provides other unique opportunities for broad scale reductions in tobacco use among youths through regulation of tobacco product design, manufacture and marketing in line with Articles 9, 10 and 11 of the WHO Framework Convention on Tobacco Control. ${ }^{22}$ The Directive includes provisions for a stronger regulation of cigarette package appearance, including prohibition of misleading elements that might imply that one brand is relatively less harmful than another. The directive has also banned the use of characterising flavours, as well as additives with purported energy, vitality or other health benefits from manufactured or roll-your-own cigarettes. ${ }^{2}$ These proposed regulatory changes are beneficial to public health since factors such as taste, smell, visual cues, as well as other sensory attributes, increase the ease of use and alter perceived risks and benefits, especially among youths. ${ }^{46102324}$ Our findings further justify the above regulatory actions.

This study is subject to a number of limitations. In relation to factors influencing initial smoking, the self-reported data assume that participants were consciously aware of what influenced their smoking-related decisions and behaviours. It is, however, reasonable to expect some degree of misreporting, even though self-reported tobacco use has been shown to correlate highly with biochemical assessments of tobacco use. ${ }^{25}$ Nonetheless, this study underscores the need for intensified efforts to regulate tobacco design features that may increase product appeal or abuse liability among young adults.

\section{What this paper adds}

\section{What is already known on this subject}

- It is well established that sensory characteristics that maintain tobacco product appeal and ease of use are important in influencing smoking behaviour independent of the direct effects of nicotine.

- Certain cigarette design and packaging characteristics could mislead consumers by suggesting benefits in terms of reduced harm perception and economic class or qualities such as femininity, elegance or masculinity.

What important gaps in knowledge exist on this topic

- Very little European Union (EU)-wide data exist on subpopulation differences in receptivity to cigarette design and marketing features in relation to initial smoking, cigarette brand choice and the perception of reduced harm among EU adults.

\section{What this study adds}

- Flavours were associated with initial smoking and reduced harm perception among younger smokers. Descriptors such as 'organic' or 'natural' cigarettes were associated with reduced harm perception among certain subpopulation groups.

- Our findings call for stronger regulation of tobacco ingredients, packaging features and other marketing strategies that may increase the attractiveness of tobacco products.

\section{CONCLUSION}

This study indicated significant associations between cigarette design and marketing features and aspects of initial smoking, cigarette brand choice and the perception of reduced harm. Flavours (including menthol) were associated with initial smoking and reduced harm perception among females and younger smokers. Furthermore, several packaging design features including the use of colours, descriptors and emission yields (eg, labelled TNCO levels) were associated with reduced harm perception among several subpopulation groups. These findings call for stronger regulation of tobacco ingredients, packaging features and other marketing strategies that may increase the attractiveness of tobacco products, including the strong implementation of the EU tobacco products directive.

Acknowledgements ITA initiated the reported research while he was affiliated with the Center for Global Tobacco Control at Harvard University. He is currently affiliated with the Centers for Disease Control and Prevention's Office on Smoking and Health. The research in this report was completed and submitted outside of the official duties of his current position and does not reflect the official policies or positions of the Centers for Disease Control and Prevention.

Contributors ITA designed the study, performed the analyses and produced the initial draft. UTO, FTF and CIV critically reviewed the manuscript, performed the data interpretation and prepared the manuscript. All authors read, edited and approved the final manuscript and are responsible for the overall content as guarantors.

\section{Competing interests None.}

Provenance and peer review Not commissioned; externally peer reviewed.

Data sharing statement All data used in these analyses are secondary, publicly available data. No additional unpublished data remain in the exclusive possession of the authors.

\section{REFERENCES}

1 Special Eurobarometer 385. ATTITUDES OF EUROPEANS TOWARDS TOBACCO. http://ec.europa.eu/public_opinion/archives/ebs/ebs_385_en.pdf (23 Aug 2013, date last accessed).

2 The European Commission. Revision of the tobacco products directive, 2014. http:// ec.europa.eu/health/tobacco/products/revision/ (14 Feb 2014, date last accessed).

3 Borland R, Savvas S. Effects of stick design features on perceptions of characteristics of cigarettes. Tob Control 2013;22:331-7.

4 Carpenter CM, Wayne GF, Connolly GN. The role of sensory perception in the development and targeting of tobacco products. Addiction 2007;102:136-47.

5 Connolly GN, Alpert HR. Has the tobacco industry evaded the FDA's ban on 'light' cigarette descriptors? Tob Control 2014;23:140-5.

6 Ford A, Mackintosh AM, Moodie C, et al. Cigarette pack design and adolescent smoking susceptibility: a cross-sectional survey. BMJ Open 2013;3:e003282.

7 Kennedy RD, Millstein RA, Rees VW, et al. Tobacco industry strategies to minimize or mask cigarette smoke: opportunities for tobacco product regulation. Nicotine Tob Res 2013;15:596-602

8 O'Connor RJ, Caruso RV, Borland R, et al. Relationship of cigarette-related perceptions to cigarette design features: findings from the 2009 ITC U.S. survey. Nicotine Tob Res 2013;15:1943-7.

9 Ahijevych K, Garrett BE. The role of menthol in cigarettes as a reinforcer of smoking behavior. Nicotine Tob Res 2010;12:110-16.

10 Kreslake JM, Wayne GF, Connolly GN. The menthol smoker: tobacco industry research on consumer sensory perception of menthol cigarettes and its role in smoking behavior. Nicotine Tob Res 2008;10:705-15.

11 Kreslake JM, Yerger VB. Tobacco industry knowledge of the role of menthol in chemosensory perception of tobacco smoke. Nicotine Tob Res 2010;12:S98-101.

12 Agaku IT, Vardavas $\mathrm{Cl}$, Ayo-Yusuf OA, et al. Gender and racial differences in smoking of long/ultra-long and king size cigarettes among U.S. adult smokers, NHANES 1999-2012. Drug Alcohol Depend 2014;136:28-35..

13 Carpenter CM, Wayne GF, Connolly GN. Designing cigarettes for women: new findings from the tobacco industry documents. Addiction 2005;100:837-51.

14 Freeman B, Chapman S, Rimmer M. The case for the plain packaging of tobacco products. Addiction 2008;103:580-90

15 Wakefield MA, Germain D, Durkin SJ. How does increasingly plainer cigarette packaging influence adult smokers' perceptions about brand image? An experimental study. Tob Control 2008;17:416-21. 
16 Adam T, McAughey J, Mocker C, et al. Influence of filter ventilation on the chemical composition of cigarette mainstream smoke. Anal Chim Acta 2010;657:36-44.

17 Marcilla A, Martínez I, Berenguer D, et al. Comparative study of the main characteristics and composition of the mainstream smoke of ten cigarette brands sold in Spain. Food Chem Toxicol 2012;50:1317-33.

18 Sokol NA, Kennedy RD, Connolly GN. The role of cocoa as a cigarette additive: opportunities for product regulation. Nicotine Tob Res 2014;16: 984-91.

19 Klausner K. Menthol cigarettes and smoking initiation: a tobacco industry perspective. Tob Control 2011;20(Suppl 2):ii12-19.

20 King B, Borland R, Abdul-Salaam S, et al. Divergence between strength indicators in packaging and cigarette engineering: a case study of Marlboro varieties in Australia and the USA. Tob Control 2010;19:398-402.
21 Agaku IT, Filippidis FT, Vardavas Cl. Effectiveness of text versus pictorial warning labels and predictors of support for plain packaging of tobacco products in 27 European Countries. Eur Addict Res 2014. In press.

22 WHO Framework Convention on Tobacco Control. http://whqlibdoc.who.int/ publications/2003/9241591013.pdf (23 Sep 2012, date last accessed).

23 Carpenter CM, Wayne GF, Pauly JL, et al. New cigarette brands with flavors that appeal to youth: Tobacco marketing strategies. Health Affairs 2005;24:1601-10.

24 Cook BL, Wayne GF, Keithly L, et al. One size does not fit all: how the tobacco industry has altered cigarette design to target consumer groups with specific psychological and psychosocial needs. Addiction 2003; 98:1547-61.

25 Caraballo RS, Giovino GA, Pechacek TF, et al. Factors associated with discrepancies between self-reports on cigarette smoking and measured serum cotinine levels among persons aged 17 years or older: Third National Health and Nutrition Examination Survey, 1988-1994. Am J Epidemiol 2001;153:807-14. 